\title{
Effect of adding a papain digest of ox liver to brain heart infusion cysteine broth on the recovery of non-sporing anaerobes from simulated blood cultures
}

\author{
DC SHANSON, JANET PRATT \\ From the Department of Medical Microbiology, Westminster Hospital Medical School, Horseferry Road, \\ London SW1P $2 A R$
}

SUMMARY Panmede, a papain digest of ox liver, added to brain heart infusion cysteine broth improved the recovery of non-sporing anaerobes from simulated blood cultures where human blood was added to each broth. The brain heart infusion broth containing both cysteine and Panmede supported the best isolation of non-sporing anaerobes during the first $48 \mathrm{~h}$ incubation compared with the four commercial media tested in parallel. Good recovery of anaerobes during the first $24 \mathrm{~h}$ was obtained with the brain heart infusion broth supplemented with cysteine and Panmede, fastidious anaerobe broth and Brewer's thioglycollate from Southern Group Laboratories but not from Thiol medium and the other type of Brewer's thioglycollate medium tested.

The addition of $0.05 \%$ cysteine to brain heart infusion blood culture broth considerably improves the growth of Bacteroides fragilis. ${ }^{1}$ Good recovery of anaerobes from simulated blood cultures using a homemade medium containing Panmede, a papain digest of ox liver, has also recently been reported. ${ }^{2}$ The purpose of the present study was to investigate the effect of adding $2.5 \%$ Panmede to brain heart infusion broth containing $0.05 \%$ cysteine on the recovery of non-sporing anaerobes from simulated blood cultures and to compare the results with those obtained using some commercial media currently available in Britain. These commercial media included fastidious anaerobe broth, Thiol under vacuum with carbon dioxide and two types of Brewer's thioglycollate media.

\section{Material and methods}

BLOOD CULTURE MEDIA

All the media were fresh and tested without liquoid. They were stored for up to two weeks in the laboratory before use.

1 Brain heart infusion broth with $0.05 \%$ cysteine Brain heart infusion broth (Bacto 0037-01, Control 657821 , Difco) was prepared by adding $37 \mathrm{~g}$ powder to $500 \mathrm{ml}$ distilled water. L-cysteine (BDH

Accepted for publication 3 February 1983
Chemicals Ltd), $0.5 \mathrm{~g}$ was dissolved in $5 \mathrm{ml} \mathrm{N} \mathrm{HCl}$ and the $5 \mathrm{ml}$ solution added to $500 \mathrm{ml}$ broth. The $\mathrm{pH}$ was adjusted to 7.4 and the final volume made up to one litre.

This broth was dispensed in $75 \mathrm{ml}$ volumes in medical flat bottles which had perforated metal caps with rubber liners. The medium was autoclaved at $121^{\circ} \mathrm{C}$ for $15 \mathrm{~min}$.

2 Brain heart infusion broth with $0.05 \%$ cysteine plus $2.5 \%$ Panmede

This medium was prepared as for (1) above but Panmede, a papain digest of ox liver (obtained from $\circ$ Paines and Byrne, Greenford, Middlesex) was added. Panmede $(50 \mathrm{~g})$ was added to $50 \mathrm{ml}$ distilled $\frac{\mathrm{O}}{\mathrm{O}}$ water and mixed. Sodium hydroxide $(40 \%), 10 \mathrm{~N}$, $4.6 \mathrm{ml}$ was added and the solution made up to 0 $100 \mathrm{ml}$ using distilled water. $50 \mathrm{ml}$ of the $50 \%$ Pan- N mede solution was added to one litre of the brain $N$ heart infusion broth containing $0.05 \%$ cysteine. The $\underset{\sigma}{\sigma}$ $\mathrm{pH}$ was adjusted to 7.8 using $10 \mathrm{~N}$ hydrochloric acid and the broth was dispensed in $75 \mathrm{ml}$ volumes in medical flat bottles. The medium was then auto- $\stackrel{\Phi}{\rightarrow}$ claved at $121^{\circ} \mathrm{C}$ for $15 \mathrm{~min}$. The $\mathrm{pH}$ of the medium was reduced by autoclaving. The autoclaved broth was checked to ensure that the working $\mathrm{pH}$ was $7 \cdot 4$.

3 Fastidious anaerobe broth with thymidine

Fastidious anaerobe broth with thymidine added 678 
(Lab M, Salford), $75 \mathrm{ml}$, commercial flat bottles of broth ready to use.

\section{Thiol medium}

Thiol broth under vacuum with carbon dioxide (Difco, code No 0355-37), $50 \mathrm{ml}$, bottles of media obtained commercially ready to use.

\section{Brewer's thioglycollate, Southern Group}

Brewer's thioglycollate from Southern Group Laboratories (Code No 0586C), $80 \mathrm{ml}$, bottles of media obtained commercially ready to use.

\section{Brewer's thioglycollate, Lab M}

Brewer's thioglycollate with thymidine from Lab $M$, $75 \mathrm{ml}$, bottles of media obtained commercially ready to use.

\section{BLOOD}

Freshly collected human blood, $5 \mathrm{ml}$, was added directly to each bottle of medium using a syringe and needle. Two donors were necessary for each experiment because of the volume of blood required and care was taken to ensure that the blood from one donor was inoculated into each of the six different media tested.

\section{BACTERIA}

The following non-sporing anaerobes were tested:

Bacteroides fragilis

NCTC 9343

Bacteroides fragilis

Bacteroides fragilis

Bacteroides melaninogenicus

Sphaerophorus necrophorus

Fusobacterium necrogenes

Laboratory strain (1)

Laboratory strain (2)

NCTC 11321

NCTC 10575

NCTC 10723

Peptostreptococcus anaerobius Laboratory strain

Peptococcus prevotii

Laboratory strain

Peptococcus asaccharolyticus Laboratory strain

Propionibacterium acnes

\section{INOCULATION}

The inoculum was calculated by 'making viable counts of dilutions of $48 \mathrm{~h}$ cooked-meat cultures of the strains to be tested by the Miles and Misra method. After preliminary tests $0 \cdot 1 \mathrm{ml}$ of the dilution likely to contain the required number of viable organisms was inoculated into the test blood broths by puncturing each cap with a separate needle attached to a disposable $1.0 \mathrm{ml}$ syringe. The actual inoculum was checked on each occasion by surface viable counts on the dilution inoculated using fresh blood agar incubated in anaerobic jars containing $10 \%$ carbon dioxide. Colonies were counted after $48 \mathrm{~h}$ incubation except for $B$ melaninogenicus which was counted after $72 \mathrm{~h}$ incubation.

METHOD FOR EACH EXPERIMENT

Each medium was tested in duplicate during each experiment. After inoculation the bottles were incubated without the use of an anaerobic jar at $35^{\circ} \mathrm{C}$. The bottles were subcultured by using a fresh needle and $1 \mathrm{ml}$ disposable syringe for each bottle. After $8 \mathrm{~h}, 1,2,3$ and 6 days and 2 weeks incubation, a $0.1 \mathrm{ml}$ sample from each bottle was spread across the surface of a freshly prepared $5 \%$ horse blood agar plate. The plates were incubated under the same conditions as the viable count plates. Growth was recorded as no growth $(-)$, scanty growth $(+)$, moderate or confluent growth $(+++)$.

\section{Results}

EFFECT OF ADDING PANMEDE TO BRAIN-HEART INFUSION CYSTEINE BROTH ON THE RECOVERY

OF ANAEROBES

Peptostreptococcus anaerobius was isolated more rapidly from the broth containing Panmede during two separate experiments (Table). There was no difference in the speed of recovery of $B$ fragilis, $B$ melaninogenicus, $S$ necrophorus or $F$ necrogenes strains from the broth with Panmede compared with the same broth without Panmede (Table). However, there was much more growth of $B$ melaninogenicus, on subculture after six days incubation, and also slightly more growth of $S$ necrophorus, on subculture after $24 \mathrm{~h}$, from the Panmede-containing medium. A repeat experiment was performed with $S$ necrophorus, using an inoculum of 22 colony forming units (CFU), and surface viable counts were carried out immediately after mixing the broths after 24 hour incubation. The viable counts were $15 \times 10^{8}$ and $15 \times 10^{8} \mathrm{CFU} / \mathrm{ml}$ for the two broths with Panmede compared with $7 \times 10^{8}$ asd $8 \times 10^{8} \mathrm{CFU} / \mathrm{ml}$ for the two broths without Panmede. The addition of Panmede to brain heart infusion cysteine broth was thus associated with superior growth during the first three days incubation of 4 of 10 strains of anaerobic organisms tested: $\boldsymbol{P}$ anaerobiosis, $\boldsymbol{B}$ melaninogenicus, $S$ necrophorus, and $P$ acnes. After $24 \mathrm{~h}$ incubation a growth of anaerobes was obtained in 22 of 24 broths containing Panmede compared with 17 of 24 identical broths without Panmede. This further indicated the superiority of the Panmede containing broth for each growth since all 24 broths of each medium had yielded growth of the anaerobes by the third day of incubation. The results did not show any disadvantage of adding Panmede to the broth for any of the strains tested at any time of subculture. 
Recovery of 10 strains of non-sporing anaerobes from six blood culture media

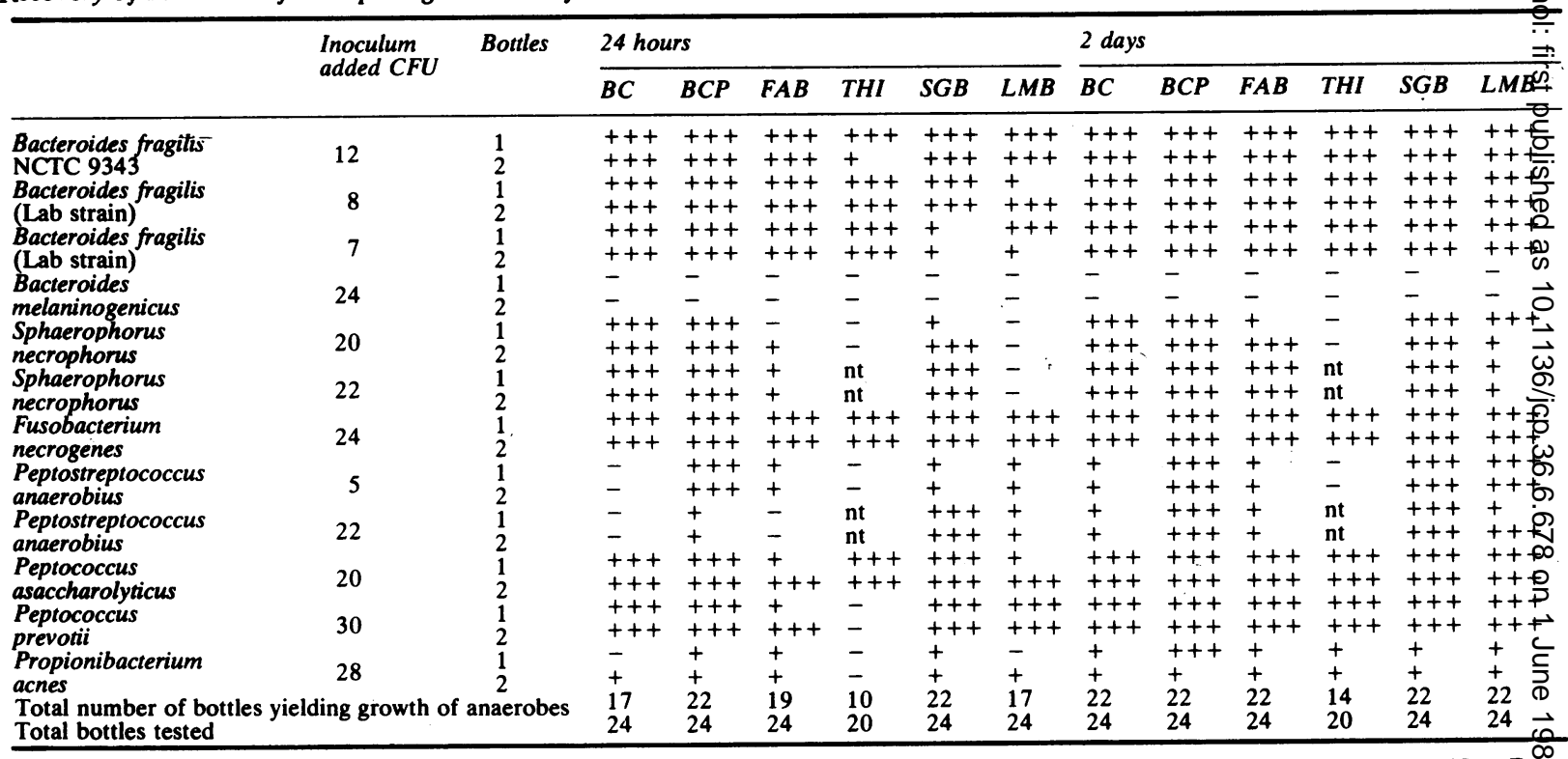

$+++=$ heavy or moderate growth; $+=$ scanty growth; $-=$ no growth; $n t=$ not tested

$L M B \equiv$ Lab M Brewer's thioglycollate. NB All subcultures were negative at $8 \mathrm{~h}$.

\section{COMPARISON OF BRAIN HEART INFUSION} CYSTEINE BROTH CONTAINING PANMEDE WITH COMMERCIALLY AVAILABLE MEDIA

Three of the six media tested were associated with the isolation of 9 of 10 strains of non-sporing anaerobes after 24 hour incubation including brain heart infusion cysteine broth containing Panmede, fastidious anaerobe broth and Brewer's thioglycollate from Southern Group Laboratories (Table). The brain heart infusion cysteine broth with Panmede and fastidious anaerobe broth gave more abundant growth of $B$ fragilis after 24 hour incubation than the Brewer's thioglycollate media. The brain-heart infusion cysteine broth with added Panmede supported the more abundant growth of $S$ necrophorus, $P$ anaerobius and $P$ asaccharolyticus after 24 hour incubation than the fastidious anaerobe broth and Brewer's thioglycollate media.

All 10 strains of non-sporing anaerobe were isolated from both Brewer's thioglycollate media after six days incubation. The Brewer's medium from Southern Group Laboratories supported more abundant growth of the $S$ necrophorus, $P$ asaccharolyticus, and $P$ acnes strains after 24 hour incubation than the Brewer's thioglycollate medium from Lab M. The Thiol medium yielded growth of only 5 of 10 strains after 24 hour incubation and was the least satisfactory medium tested in this study.

All the inoculated broths of the six media tested yielded moderate growth of the anaerobes after two weeks incubation except for the two bottles of Thiol with $S$ necrophorus added which yielded no growth.

\section{Discussion}

The addition of Panmede to the brain heart infusion. cysteine blood culture broth improved the early growth of the $P$ anaerobius, $B$ melaninogenicus and $S$ necrophorus strains tested and this was probably due to growth-promoting nutrient factors rather than increased anaerobiosis. This broth containing Panmede gave excellent recovery of non-sporing anaerobes in the simulated blood culture experiments as 9 of 10 strains were isolated from all the broths by 24 hour incubation and the tenth strain, $B$ melaninogenicus was isolated by the third day. Commercially available ready-to-use broths which gave results almost as good as the brain-heart infusion cysteine broth with Panmede were fastidious anaerobe broth and Brewer's thioglycollate from Southern Group Laboratories. Good results with fastidious anaerobe broth have been reported in other recent studies. ${ }^{23}$

The amount of growth of $B$ fragilis after 24 hour incubation in Brewer's thioglycollate from Southern Group Laboratories was less than that observed with the brain-heart infusion cysteine broth media. However, 22 of 24 inoculated Southern Group Brewer's thioglycollate bottles yielded anaerobes after $24 \mathrm{~h}$ compared with 19 positive fastidious 


\begin{tabular}{|c|c|c|c|c|c|c|c|c|c|c|c|c|c|c|}
\hline & \multirow{2}{*}{$\begin{array}{l}\text { Inoculum } \\
\text { added CFU }\end{array}$} & \multirow[t]{2}{*}{ Bottles } & \multicolumn{6}{|l|}{3 days } & \multicolumn{6}{|l|}{6 days } \\
\hline & & & $B C$ & $B C P$ & $F A B$ & $T H I$ & $S G B$ & $L M B$ & $B C$ & $B C P$ & $F A B$ & $T H I$ & $S G B$ & $L M B$ \\
\hline $\begin{array}{l}\text { Bacteroides fragilis } \\
\text { NCTC 9343 } \\
\text { Bacteroides fragilis } \\
\text { (Lab strain) } \\
\text { Bacteroides fragilis } \\
\text { (Lab strain) } \\
\text { Bacteroides } \\
\text { melaninogenicus } \\
\text { Sphaerophorus } \\
\text { necrophorus } \\
\text { Sphaerophorus } \\
\text { necrophorus } \\
\text { Fusobacterium } \\
\text { necrogenes } \\
\text { Peptostreptococcus } \\
\text { anaerobius } \\
\text { Peptostreptococcus } \\
\text { anaerobius } \\
\text { Peptococcus } \\
\text { asaccharolyticus } \\
\text { Peptococcus } \\
\text { Prevotii } \\
\text { Propionibacterium } \\
\text { acnes } \\
\text { Total number of bo } \\
\text { Total bottles tested }\end{array}$ & $\begin{array}{r}12 \\
8 \\
7 \\
24 \\
20 \\
22 \\
24 \\
5 \\
22 \\
20 \\
30 \\
28 \\
\text { ing growth of }\end{array}$ & $\begin{array}{l}1 \\
2 \\
1 \\
2 \\
1 \\
2 \\
1 \\
2 \\
1 \\
2 \\
1 \\
2 \\
1 \\
2 \\
1 \\
2 \\
1 \\
2 \\
1 \\
2 \\
1 \\
2 \\
1 \\
2 \\
\text { 1aerobes }\end{array}$ & $\begin{array}{l}+++ \\
+++ \\
+++ \\
+++ \\
+++ \\
+++ \\
+ \\
+ \\
+++ \\
+++ \\
+++ \\
+++ \\
+++ \\
+++ \\
+++ \\
+++ \\
+++ \\
+++ \\
+++ \\
+++ \\
+++ \\
+++ \\
+++ \\
+++ \\
24 \\
24\end{array}$ & $\begin{array}{l}+++ \\
+++ \\
+++ \\
+++ \\
+++ \\
+++ \\
+ \\
+ \\
+++ \\
+++ \\
+++ \\
+++ \\
+++ \\
+++ \\
+++ \\
+++ \\
+++ \\
+++ \\
+++ \\
+++ \\
+++ \\
+++ \\
+++ \\
+++ \\
24 \\
24\end{array}$ & 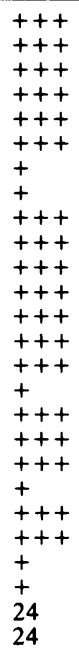 & $\begin{array}{l}+++ \\
+++ \\
+++ \\
+++ \\
+++ \\
+++ \\
- \\
- \\
- \\
- \\
\text { nt } \\
\text { nt } \\
+++ \\
+++ \\
- \\
- \\
\text { nt } \\
\text { nt } \\
+++ \\
+++ \\
+++ \\
+++ \\
+ \\
+ \\
14 \\
20\end{array}$ & $\begin{array}{l}+++ \\
+++ \\
+++ \\
+++ \\
+++ \\
+++ \\
- \\
+ \\
+++ \\
+++ \\
+++ \\
+++ \\
+++ \\
+++ \\
+++ \\
+++ \\
+++ \\
+++ \\
+++ \\
+++ \\
+++ \\
+++ \\
+++ \\
+++ \\
23 \\
24\end{array}$ & 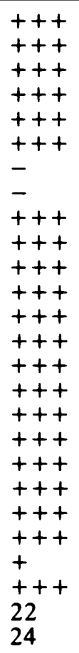 & $\begin{array}{l}+++ \\
+++ \\
+++ \\
+++ \\
+++ \\
+++ \\
+ \\
+ \\
+++ \\
+++ \\
+++ \\
+++ \\
+++ \\
+++ \\
+++ \\
+++ \\
+++ \\
+++ \\
+++ \\
+++ \\
+++ \\
+++ \\
+++ \\
+++ \\
24 \\
24\end{array}$ & 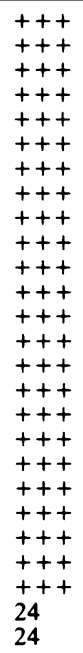 & 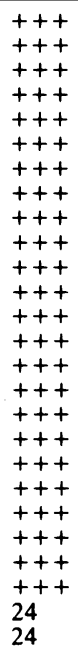 & $\begin{array}{l}+++ \\
+++ \\
+++ \\
+++ \\
+++ \\
+++ \\
++t \\
+++ \\
+ \\
- \\
\mathrm{nt} \\
\mathrm{nt} \\
+++ \\
+++ \\
+++ \\
+++ \\
\mathrm{nt} \\
\mathrm{nt} \\
+++ \\
+++ \\
+++ \\
+++ \\
+++ \\
+++ \\
18 \\
20\end{array}$ & $\begin{array}{l}+++ \\
+++ \\
+++ \\
+++ \\
+++ \\
+++ \\
+++ \\
+++ \\
+++ \\
+++ \\
+++ \\
+++ \\
+++ \\
+++ \\
+++ \\
+++ \\
+++ \\
+++ \\
+++ \\
+++ \\
+++ \\
+++ \\
+++ \\
+++ \\
24 \\
24\end{array}$ & $\begin{array}{l}+++ \\
+++ \\
+++ \\
+++ \\
+++ \\
+++ \\
+++ \\
+++ \\
+ \\
+ \\
+++ \\
+++ \\
+++ \\
+++ \\
+++ \\
+++ \\
+++ \\
+++ \\
+++ \\
+++ \\
+++ \\
+++ \\
+++ \\
+++ \\
24 \\
24\end{array}$ \\
\hline
\end{tabular}

heart infusion cysteine and Panmede broth; FAB = Fastidious anaerobe broth; THI = Thiol medium; SGB = Southern Group Brewer's thioglycollate;

anaerobe broth bottles. This Brewer's medium was recommended in the $A C P$ Broadsheet ${ }^{4}$ in 1974 but conflicting results have been obtained with it by different workers over the last $10 \mathrm{yr}^{235}$ It is possible that different batches produced by the manufacturer have varied in their performance over the last decade. Other possible explanations for different results by different workers include variations in the strains of anaerobes selected, the inocula used, the freshness of the medium, the method of subculture, the concentration of blood in the medium and whether fresh human blood or stored defibrinated horse blood was used for simulated blood culture experiments.

Previous reports have suggested that Thiol medium is satisfactory for the isolation of anaerobes from blood cultures ${ }^{67}$ although the duration of storage of this medium before use greatly affects the results obtained. ${ }^{8}$ In one report a much higher recovery rate of anaerobes was obtained from brain heart infusion broth mixed with fresh cooked meat broth than with Thiol. ${ }^{9}$ In the present study Thiol medium urder vacuum with carbon dioxide yielded poor growth of non-sporing anaerobes, other than $B$ fragilis, as five strains could not be isolated after 24 hour incubation. One of the five strains included Peptostreptococcus anaerobius and it is noteworthy that strains of this species of anaerobic coccus also failed to be isolated during the first two days incubation of Thiol medium in two recent reports. ${ }^{23}$ These reports as well as the present study found that Thiol medium generally gave less reliable recovery of anaerobes from simulated blood cultures than fastidious anaerobe broth. However, the volume of Thiol medium, $50 \mathrm{ml}$, was less than with the other media tested in parallel. This volume is the one in most common use in Britain for the culture of $5 \mathrm{ml}$ blood. It is possible that the fresh human blood added may have had an increased antibacterial effect against the small inocula of anaerobes added as the blood was diluted only $1 / 10$ in this media compared with $1 / 18$ in the other media.

\section{References}

' Shanson DC, Singh J. Effect of adding cysteine to brain-heart infusion broth on the isolation of Bacteroides fragilis from experimental blood cultures. J Clin Pathol 1981;34:221-3.

${ }^{2}$ Hunt GH, Price EH. Comparison of a homemade blood culture broth containing a papain digest of liver, with four commercially available media for the isolation of anaerobes from simulated paediatric blood cultures. J Clin Pathol 1982;35:1142-9.

${ }^{3}$ Ganguli L, Turton LJ, Tillotson GS. Evaluation of fastidious anaerobe broth as a blood culture medium. J Clin Pathol 1982;35:458.

4 Stokes EJ. Blood culture technique. ACP Broadsheet 81, 1974.

${ }^{5}$ Shanson DC. An experimental assessment of different anaerobic blood culture methods. J Clin Pathol 1974;27:273-9.

- Shanson DC, Barnicoat M. An experimental comparison of Thiol broth with Brewer's thioglycollate for anaerobic blood cultures. J Clin Pathol 1975;28:407.

${ }^{7}$ Szawatowski MV. A comparison of three readily available types 
of anaerobic blood culture media. Med Lab Sciences 1976;33:5.

${ }^{8}$ Barr JG. A cooked meat blood culture medium; shelf-life and clinical evaluation compared with other systems. J Infect 1980;2:247-58.

${ }^{9}$ Collee JG, Duerden BI, Brown R. Recovery of anaerobic bac-
. teria from small inocula: a model for blood culture studies. $J$ Clin Pathol 1977;30:609.

Requests for reprints to: Dr DC Shanson, Department of Medical Microbiology, Westminster Hospital Medical School, Horseferry Road, London SW1P 2AR, England 